\title{
Bronquiectasias no relacionadas con fibrosis quística en niños: guías de diagnóstico, seguimiento y tratamiento
}

Bronchiectasis not related to cystic fibrosis in children: Guidelines for diagnosis, monitoring and treatment

Comité de Neumonología

\section{RESUMEN}

Las bronquiectasias se encuentran dentro del espectro de enfermedad pulmonar crónica caracterizada por la dilatación bronquial progresiva y, a menudo, irreversible, causada por cambios estructurales en la pared bronquial e inflamación crónica de las vías respiratorias. El síntoma cardinal es la tos crónica persistente húmeda y productiva, que debe alertar para realizar una intervención oportuna e interrumpir el ciclo de inflamación, infección y daño de la vía aérea. Un diagnóstico precoz a través de la tomografía axial computarizada de alta resolución de tórax y el monitoreo clínico facilitan la implementación de un tratamiento intensivo que reduce y minimiza el daño de la vía aérea. Si bien las acciones terapéuticas actuales para el manejo de bronquiectasias son efectivas, existen pocos estudios clínicos aleatorizados en pediatría. El objetivo del documento es proporcionar una actualización sobre el diagnóstico, seguimiento y tratamiento de las bronquiectasias no relacionadas con fibrosis quística en niños.

Palabras clave: bronquiectasia, niño, guía, seguimiento.

\begin{abstract}
Bronchiectasis is within the spectrum of chronic lung disease characterized by progressive and often irreversible bronchial dilation caused by structural changes in the bronchial wall and chronic inflammation of the airways. The cardinal symptom is persistent moist and productive chronic cough that should alert to timely intervention and interrupt the cycle of inflammation, infection, and airway damage. Early diagnosis through high-resolution computed tomography of the chest and clinical monitoring facilitate the implementation of intensive treatment that reduces and minimizes damage to the airway. Although current therapeutic actions for the management of bronchiectasis are effective, there are few randomized clinical trials in pediatrics. The objective of the document is to provide an update on the diagnosis, monitoring and treatment of bronchiectasis not related to cystic fibrosis in children.

Keywords: bronchiectasis, child, guideline, follow-up.

http: / / dx.doi.org/10.5546/ aap.2020.S164

Cómo citar: Comité de Neumonología. Bronquiectasias no relacionadas con fibrosis quística en niños: guías de diagnóstico, seguimiento y tratamiento. Arch Argent Pediatr 2020;118(6):S164-S182.
\end{abstract}

a. Miembros del Comité Nacional de Neumonología, Sociedad Argentina de Pediatría.

Correspondencia: Dra. Silvina Smith: smithsilvina@hotmail. com

Financiamiento:

Ninguno.

Conflicto de intereses: Ninguno que declarar.

Recibido: 22-7-2020

Aceptado: $31-7-2020$

\section{Comité de Neumonología}

Coordinadores: Dra. Smith, Silvina ${ }^{a}$; Dr. Salim, Maximiliano ${ }^{a}$, Dra. Bujedo, Elizabeth ${ }^{a}$. Secretaria del Comité Nacional de Neumonología: Dra. MartinchukMigliazza, Gisela. Colaborador: Grupo de Trabajo de Kinesiología.

Participantes en la discusión y redacción de este Consenso:

Comité Nacional de Neumonología: Abram, Lina; Agüero, Luis; Arato, Gisela; Bigas, Fabio; Blasco, Teresa; Bodas, Pablo; Borda, Mauricio; Bosh, Juan; Calvo, Mariel; Calleri, Bruno; Castiglioni, Nicolás; Cipriani, Silvina; D'Alessandro, Virginia; Dicembrino, Manuela; Donth Leger, Gimena; Ferretti, Diego; Fiamingo, Alfio; Fraga, Marcela; Giubergia, Verónica; Giugno, Hilda; González, Norma; Kohn, Verónica; Kruger, Anahi; Lagrutta, Laura; López, Mariela; Loto, Yanina; Lucero, Belén; Luque, Graciela; Macha, Edith; Magadan, Corina; Martinchuk Migliazza, Gisela; Melillo, Karina; Moreno, Laura; Paba, Patricia; Parra, Luis; Piñón, Stella; Selvino, Verónica; Szulman, Gabriela; Rivas, Elisa; Robles, Raúl; Ruocco, Mariela; Toloza, Rodolfo; Vila, Fernando.

Grupo de Trabajo de Kinesiología: Tognini, Carla; Nociti, Yamila; Garetto, Sofía; Olguín Ciancio, Maite; Pinto, Fabiana. 


\section{INTRODUCCIÓN}

Las bronquiectasias se encuentran dentro del espectro de enfermedad pulmonar crónica caracterizada por la dilatación bronquial progresiva y, a menudo, irreversible, causada por cambios estructurales en la pared bronquial e inflamación crónica de las vías respiratorias. ${ }^{1}$ Las bronquiectasias no relacionadas con la fibrosis quística (bronquiectasias no FQ) han ganado importancia en la última década, debido a que su incidencia es más elevada de lo que se estimaba anteriormente. ${ }^{1}$ Distintos registros han proporcionado información, y este aumento puede atribuirse, en parte, a la mayor disponibilidad de estudios complementarios, como la tomografía axial computarizada de alta resolución (TACAR), para realizar el diagnóstico. ${ }^{1,2}$

Las bronquiectasias, a menudo, se originan en la infancia y sus síntomas pueden perdurar y el diagnóstico puede postergarse hasta la vida adulta. ${ }^{3}$ Tradicionalmente, se definían como dilataciones irreversibles de los bronquios periféricos, pero, en la actualidad, se ha comprobado en niños que, en estadios iniciales, se pueden prevenir o incluso pueden ser reversibles tratando la causa subyacente de forma adecuada y precoz. ${ }^{4}$

Aunque los conocimientos sobre bronquiectasias no FQ en pediatría están aumentando, existen controversias con respecto a su etiología, diagnóstico y tratamiento. Las recomendaciones se basan en la opinión de expertos y son extrapoladas de las normas existentes en adultos y en la comparación con otras enfermedades respiratorias crónicas, como, por ejemplo, la FQ. El objetivo de este documento es proporcionar una actualización sobre el diagnóstico, el seguimiento y el tratamiento de las bronquiectasias no FQ con el fin de mejorar la calidad de atención de los pacientes y crear conciencia de prevención para aquellos que están en riesgo de padecerla.

\section{EPIDEMIOLOGÍA}

Las bronquiectasias no FQ afectan a todas las etnias y entornos socioeconómicos. La incidencia y la prevalencia varían entre las poblaciones. Estudios en Nueva Zelanda mostraron una desproporción considerable en la incidencia anual promedio entre los niños maoríes e isleños del Pacífico (4,8-7,9/100 000 vs. 17,8-18,3/100 000). En los niños inuit canadienses en la región de Banff, la incidencia alcanza a 200/100 000, mientras que, para los niños aborígenes de Australia Central y del sudoeste de Alaska, alcanza, aproximadamente, 1,5/100 000. La incidencia entre las poblaciones europeas se estima en alrededor de 0,2/100000 en el Reino Unido y de 2,3/100 000 en Irlanda. ${ }^{5}$ En otros países desarrollados, como Finlandia, tienen tasas aún más bajas $(0,5 / 100000) .{ }^{6}$ Esta diferencia parece estar directamente relacionada con los niveles socioeconómicos y de atención médica, que son inferiores en estas poblaciones.

No existen datos epidemiológicos específicos en Latinoamérica. La mortalidad por bronquiectasias también varía entre las poblaciones. De las 5745 muertes atribuidas a bronquiectasias en Inglaterra y Gales entre 2001 y 2007, solo 12 estaban en el grupo de edad de 0 a 14 años. Un estudio de Malasia observó una considerable morbilidad con un impacto negativo sobre el crecimiento, la función pulmonar, la calidad de vida, la desnutrición y la osteopenia. ${ }^{7,8}$ La frecuencia es mayor en el sexo masculino en la niñez, y la relación se invierte en la adultez y prevalece en el sexo femenino. ${ }^{5,9}$

\section{PATOGENIA}

La patogénesis de las bronquiectasias se basa en un ciclo propuesto por Cole que involucra la inflamación, la infección y el daño estructural. Puede explicarse de la siguiente manera: la inflamación desencadenada por un agente microbiano o por otra lesión local da como resultado un aclaramiento mucociliar alterado. La disminución del aclaramiento de las vías respiratorias conduce a un aumento de la colonización bacteriana e infección secundaria, por lo que se establece un "ciclo vicioso" de infección e inflamación no controlada de las vías respiratorias, lo que lleva a una destrucción progresiva de las paredes bronquiales, que resulta en la dilatación y la acumulación de secreciones, que provoca la obstrucción del flujo de aire. ${ }^{10}$

La alta carga bacteriana que se acumula en las vías respiratorias estimula la producción de mediadores proinflamatorios, que incluyen metaloproteinasa de matriz (matrix metalloproteinases; $M M P$, por sus siglas en inglés) octatandina, factor de necrosis tumoral-alfa (tumor necrosis factor alpha; TNF- $\alpha$, por sus siglas en inglés) e interleuquina 8 (IL-8). El TNF- $\alpha$ estimula la secreción de proteasas por los neutrófilos y una disminución de la concentración de inhibidor de la leucoproteasa secretora, que puede conducir a una lesión no controlada de las vías respiratorias 
mediada por elastasa. Esta mayor concentración de elastasa (derivada de neutrófilos y bacterias) puede inducir hipersecreción de moco, deteriorar la función ciliar, afectar las inmunoglobulinas locales y reducir la opsonofagocitosis, lo que produce daño epitelial continuo ${ }^{11}$ (Figura 1).

Esta cascada de eventos continuos lleva a cambios estructurales de la vía aérea y diversos grados de dilatación e inflamación de la pared bronquial, y esto se inicia, principalmente, en las vías aéreas periféricas. ${ }^{12}$ Los primeros cambios de las bronquiectasias consisten en el engrosamiento de la pared bronquiolar por edema y formación de folículos linfáticos que se hipertrofian y obstruyen la luz de la vía aérea. Además, hay destrucción de la elastina. Ante la persistencia de la lesión, se produce daño muscular y del cartílago, que, finalmente, determina la dilatación bronquial. ${ }^{13}$

Los cambios vasculares asociados pueden incluir arterias bronquiales dilatadas y neovascularización con anastomosis broncopulmonares en las ramas distales de los bronquios. Se cree que las anastomosis son el resultado del aumento de las demandas metabólicas del músculo hipertrofiado, el tejido linfoide y el tejido de granulación peribronquial asociado con la bronquiectasia. ${ }^{12,13}$

En casos graves, podría observarse desarrollo de hipertensión pulmonar (HTP). Este último es un marcador pronóstico tardío en bronquiectasias y es más probable en adultos y o en etapas avanzadas de la enfermedad. ${ }^{11,14,15}$ Sin embargo, es poco frecuente en pediatría. Un estudio de 40 niños australianos indígenas, algunos de los cuales tenían bronquiectasias graves, encontró solo un caso con HPT. ${ }^{14}$

Desde la comprensión de la patogenia de las bronquiectasias a través de la hipótesis del ciclo de Cole, se planteó un espectro de enfermedad con gravedad creciente. ${ }^{10}$ En un extremo, se encontrarían la bronquitis bacteriana prolongada (BBP) y la enfermedad pulmonar supurativa crónica, y, en el otro extremo, la expresión más grave, que son las bronquiectasias. ${ }^{16}$ Esto fue respaldado por un estudio longitudinal en 161 niños con BBP que mostró que el 8,1\% desarrollaron bronquiectasias a los 2 años de seguimiento. ${ }^{17,18}$ (Figura 2).

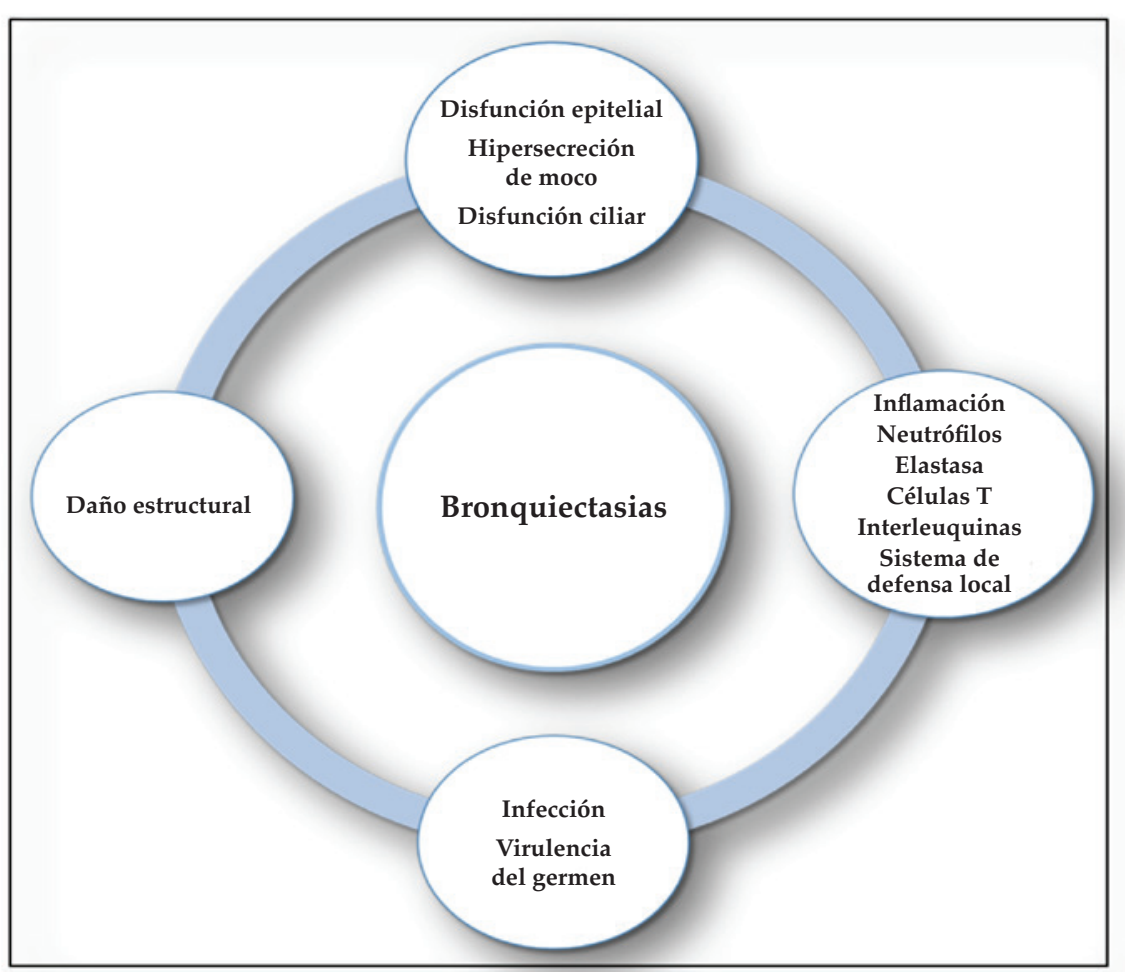

Fuente propia. 
La BBP se define como la presencia de tos húmeda crónica (es decir, que dura más de 4 semanas), que se resuelve clínicamente (no existen cambios radiológicos) con dos semanas de tratamiento antibiótico, en ausencia de otras causas alternativas de tos. ${ }^{17,18}$ La enfermedad pulmonar supurativa crónica es el término dado para aquellos pacientes que tienen las características clínicas de tos húmeda prolongada similar a las bronquiectasias, pero sin cambios tomográficos evidentes. ${ }^{19,20,21}$ Las bronquiectasias forman parte de un síndrome caracterizado clínicamente por episodios de tos húmeda prolongada sensible a antibióticos (por lo general, $>3$ por año) junto con imágenes compatibles, es decir, con hallazgos característicos en la tomografía de tórax de alta resolución que muestra la dilatación anormal de uno o más bronquios. ${ }^{21}$

Los niños con más 3 episodios de BBP por año y aquellos con infección de las vías aéreas inferiores por $H$. influenzae versus aquellos que no los presentan tienen un mayor riesgo de bronquiectasias: 9,77 (intervalo de confianza -IC- del $95 \%$ : 2,13-44,80) y 7,55 (1,66$34,28)$, respectivamente, luego de 2 años de seguimiento. ${ }^{20,21}$ Además, se ha demostrado que la tos húmeda crónica que no responde a un curso de 4 semanas de antibióticos puede predecir la presencia de bronquiectasias. ${ }^{4}$

Un porcentaje importante de eventos infecciosos que afectan la vía aérea alta y baja son responsables de síntomas respiratorios (aumento de secreciones, tos, fiebre) con la característica clínica de que son autolimitados y se resuelven sin tratamientos específicos. La BBP es un diagnóstico clínico para considerar, sobre todo, en los primeros años de vida, tiempo durante el cual los sistemas respiratorio e inmunitario están madurando y la vía respiratoria es vulnerable a lesiones. ${ }^{18,20}$ El tratamiento oportuno de la BBP reduciría la morbilidad a corto y largo plazo, y evitaría el desarrollo de bronquiectasias. ${ }^{4,21}$
Eastham y col., realizaron una revisión clínica y por imágenes de 93 niños con diagnóstico de bronquiectasias por TACAR de tórax y observaron, en 6 pacientes con descripciones de engrosamiento peribronquial y dilatación cilíndrica de la vía aérea, a los 18 meses de repetición de la tomografía, una reversibilidad de las lesiones. ${ }^{4}$

En un estudio que incluyó bronquiectasias diagnosticadas en adultos, aquellos con tos crónica desde la infancia tenían una enfermedad significativamente mayor (más exacerbaciones, función pulmonar inferior y peor puntaje tomográfico) en comparación con aquellos sin síntomas en la edad pediátrica., ${ }^{4,22}$ Por lo tanto, estadios iniciales de la enfermedad, como la BBP, y la enfermedad pulmonar supurativa crónica deben recibir tratamiento oportunamente con el fin de evitar la progresión al daño irreversible con bronquiectasias. ${ }^{4,23}$

\section{ETIOLOGÍA}

Durante muchos años, las bronquiectasias fueron consideradas una enfermedad huérfana, sin poder identificarse su etiología. En la actualidad, con la ayuda de métodos complementarios y TACAR, en la mayoría de los casos, existe una causa subyacente. ${ }^{11}$ Recientemente, Lonni et al., realizaron un análisis de 1258 pacientes (niños y adultos) de siete cohortes de diferentes países, incluidos en el Registro Europeo de Bronquiectasias (European Multicentre Bronchiectasis Audit and Research Collaboration, EMBARC), el estudio más extenso dirigido a la identificación de etiologías de bronquiectasias hasta la fecha. ${ }^{24}$ Este estudio ha demostrado que la causa de bronquiectasias puede ser identificada en, aproximadamente, el $60 \%$ de las personas.

En una revisión sistemática de Bower et al., que incluyó 12 estudios con 989 niños, se observó que el $63 \%$ tenía una enfermedad subyacente. ${ }^{25}$ Las causas halladas con más

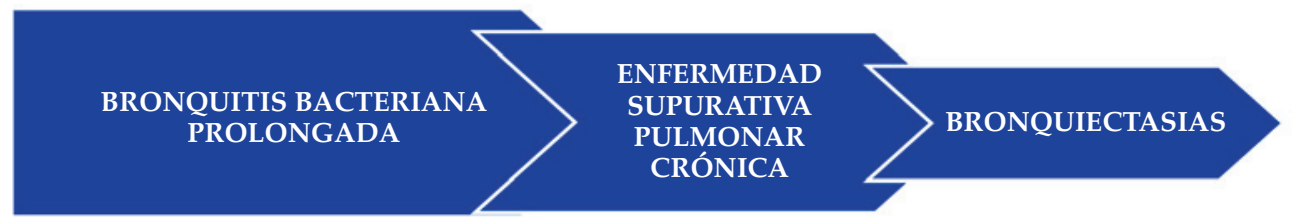


frecuencia fueron infecciones respiratorias bajas en el $19 \%$, inmunodeficiencias primarias en el $17 \%$, síndrome aspirativo crónico, incluido el cuerpo extraño en el $10 \%$ y la disquinesia ciliar primaria (DCP) en el $7 \% .{ }^{25}$ La mayor revisión en nuestro país, con 687 niños, publicada en 2003 por Murtagh et al., mostró que la etiología posinfecciosa era la más frecuente en pediatría, en coincidencia con datos actuales. ${ }^{26}$
En todos los niños con sospecha o confirmación de bronquiectasias por TACAR, se debe identificar la etiología. Sin embargo, en un $30-50 \%$ de los casos pediátricos, no se identifica la causa tras una evaluación adecuada ${ }^{27}$ (Tabla 1).

En distintas series de estudios de niños previamente sanos, la causa más frecuente de bronquiectasias suele ser la posinfecciosa.

TABLA 1. Etiología y clasificación

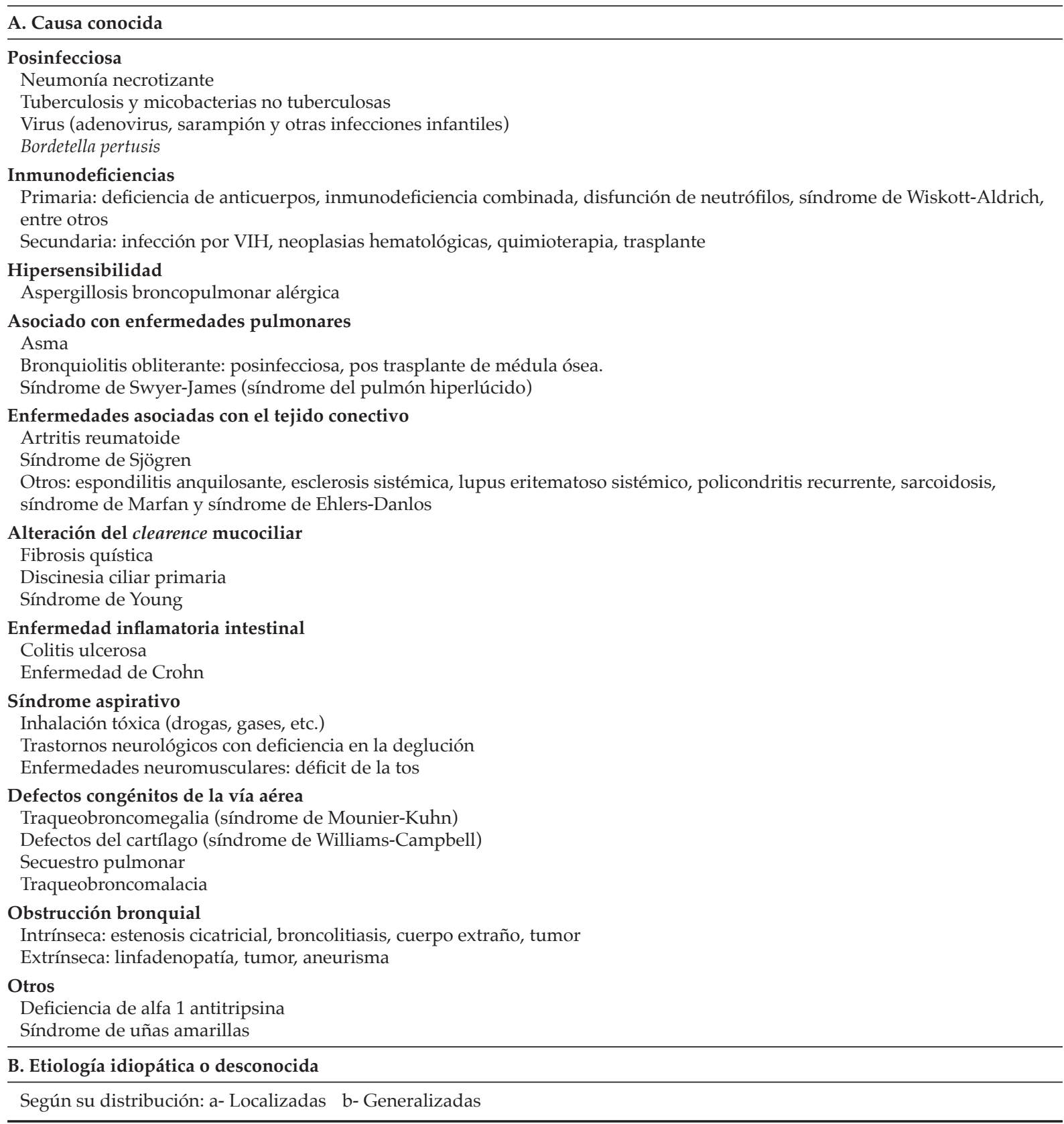

Adaptado de Suárez-Cuartin G, et al. Diagnostic challenges of bronchiectasis. http:/ / dx.doi.org/10.1016/j.rmed.2016.05.014. VIH: virus de la inmunodeficiencia humana. 
Para demostrar la etiología, debe haber una relación temporal entre la infección y el posterior desarrollo de bronquiectasias. Los agentes involucrados pueden ser de origen viral, bacteriano o las micobacterias del complejo tuberculosis y micobacterias no tuberculosas, estas últimas, especialmente, en casos con enfermedades predisponentes. Los agentes más frecuentes son adenovirus, B. pertussis, virus del sarampión y la infección por virus de la inmunodeficiencia humana (VIH). Las bronquiectasias posinfecciosas han disminuido en los países desarrollados como consecuencia de los programas de inmunización (sarampión, tos ferina), una utilización racional de antibióticos, la mejoría de las condiciones socioeconómicas y el acceso a la salud. ${ }^{1,25,27}$

Las inmunodeficiencias primarias y secundarias son la segunda causa de bronquiectasias según las distintas series en pediatría, pero, en países desarrollados y en pocos estudios, figura como primera causa.$^{28} \mathrm{La}$ función inmune alterada se asocia con infecciones respiratorias recurrentes, crónicas y graves que conducen a episodios de inflamación de las vías respiratorias, reparación y, en última instancia, daño estructural. Los trastornos inmunes más frecuentes incluyen producción o función alterada de todas las clases de inmunoglobulinas, clases individuales o subclases y defectos de producción de anticuerpos específicos, como el polisacárido capsular bacteriano. Es por ello por lo que, dentro del plan de estudio de bronquiectasias no FQ, se realizarán estudios inmunológicos que incluyan funcionalidad humoral y celular, ampliando de acuerdo con resultados y antecedentes clínicos.

Se ha demostrado que la aspiración del contenido gastrointestinal y orofaríngeo es una causa de bronquiectasia en niños y adultos que presentan, por ejemplo, alteraciones del clearance esofágico y fístulas traqueoesofágicas. Niños con patologías neurológicas o enfermedades neuromusculares tienen afectado el reflejo de la tos y presentan mayor predisposición a trastornos en la deglución que los hacen más susceptibles a la aspiración recurrente de contenido gástrico y orofaríngeo, lo que favorece el desarrollo de infecciones respiratorias recurrentes y bronquiectasias posteriormente. . $^{1,25,27,28}$

La DCP es una entidad menos frecuente que se caracteriza por una anormalidad congénita de la función ciliar, que causa deterioro del aclaramiento mucociliar y predisposición a infecciones respiratorias recurrentes. A menudo, comienza en los primeros años de vida. Una historia de dificultad respiratoria neonatal sin prematuridad con dextrocardia o situs inversus (el $50 \%$ de los casos) y problemas recurrentes del oído medio son muy sugerentes para este diagnóstico. Asimismo, pueden observarse rinosinusitis crónica y bronquiectasias en niños mayores. ${ }^{29}$ En todos los casos en que se sospeche este diagnóstico, es necesaria la derivación a centros de referencia debido a las dificultades para acceder a los estudios complementarios para su confirmación. ${ }^{2}$

\section{CLÍNICA}

El conocimiento de los síntomas y signos de las bronquiectasias no FQ es clave y debe alertar a los médicos para evaluar al niño en busca de bronquiectasias. La tos crónica húmeda o productiva es el síntoma dominante. Puede ser intermitente después del tratamiento o que no responda a los antibióticos. ${ }^{1,2} \mathrm{La}$ BBP ( $>3$ episodios por año) y una tos húmeda o productiva que no responde a 2-4 semanas de antibióticos orales predice la presencia de bronquiectasias definidas por TACAR de tórax. ${ }^{20}$ Otras manifestaciones que pueden hallarse son disnea o intolerancia al ejercicio, expectoración mucopurulenta, fiebre, halitosis, falla en el crecimiento, neumonía recurrente y, en la enfermedad avanzada, hemoptisis. En el examen físico, dependiendo de la causa y también de la localización, se puede observar disminución del murmullo vesicular, subcrepitantes, sibilancias que no se modifican con la tos y signos de enfermedad pulmonar crónica, como disminución de la elasticidad, aumento del diámetro anteroposterior del tórax e hipocratismo digital no tan notorios como en la FQ. ${ }^{1,2,20,22,23}$

Las comorbilidades son importantes y pueden no estar directamente relacionadas con los marcadores de gravedad de las bronquiectasias no FQ. Estos incluyen hiperreactividad de las vías respiratorias, rinorrea posterior, desnutrición, hipoxemia, HTP, trastornos relacionados con el sueño, reflujo gastroesofágico, factores psicosociales, calidad de vida y los signos de progresión de la causa subyacente que motivó el desarrollo de bronquiectasias, como complicaciones extrapulmonares, y que deben ser parte de una revisión clínica. ${ }^{30}$

\section{DIAGNÓSTICO}

Los signos y síntomas cardinales de alerta se encuentran siempre presentes en el diagnóstico 
de bronquiectasias no FQ durante la infancia. La tos crónica productiva constituye el principal síntoma. Tres o más episodios de BBP anuales y/o tos productiva que no responde a 4 semanas de tratamiento antibiótico predicen la presencia de bronquiectasias. ${ }^{18,31,32}$ La presencia de imágenes radiológicas más allá de las 6 semanas de una terapia apropiada constituye también un indicador de daño. ${ }^{1}$

El principal estudio complementario (gold standard) para confirmar la presencia de bronquiectasias es la TACAR de tórax. Los principales hallazgos son los siguientes: 1) cociente bronquio-arteria aumentado (definido como el cociente entre el diámetro interno de la vía aérea sobre el diámetro externo del vaso acompañante) dentro de los $5 \mathrm{~mm}$ y en un plano no tangencial, signo conocido como el anillo de sello; 2) engrosamiento de la pared bronquial; 3) falta de disminución del calibre desde el centro hacia la periferia; 4) visualización de estructuras bronquiales en la periferia pulmonar; 5) hipoperfusión en mosaico (como expresión de atrapamiento aéreo), sobre todo, en cortes en espiración.

Las bronquiectasias pueden clasificarse en tres grandes grupos: cilíndricas, varicosas y quísticas. Esta misma escala puede ser un elemento de evaluación de gravedad en el orden mencionado, y debe destacarse que la observación del daño no es únicamente a través de los estudios de imágenes. La identificación del cociente broncoarterial (bronchio-arterial ratio $-B A R-$ ) es todavía controversial, ya que la definición surgió de estudios realizados en seis adultos con bronquiectasias en los que se tomó un valor de corte entre 1 y 1,5 en ese cociente. ${ }^{33}$ Durante muchos años, no se consideró que la vía aérea de los niños tenía otras condiciones estructurales y otras características particulares. El punto de corte para utilizar en pediatría sería $0,8.33,34$

La presencia de bronquiectasias en la edad pediátrica debe ser siempre confirmada con estudios de adecuada calidad de imágenes (TACAR de tórax) y, a diferencia de lo que se propone en adultos, se plantea la necesidad de obtener estudios en forma pareada (con un intervalo de entre 3 y 4 años) para consignar su irreversibilidad. Varias publicaciones sostienen que un tratamiento agresivo en etapas iniciales de la enfermedad (bronquiectasia cilíndrica) podría minimizar el daño y revertir los hallazgos del estudio inicial. ${ }^{4}$

Los estudios complementarios deben ir orientados sobre la base de los antecedentes personales y del entorno socioeconómico del niño: por ejemplo, evaluar la consanguinidad en casos de trastornos de la inmunidad. En casos con dextrocardia y situs inversus, debe evaluarse la funcionalidad ciliar. Existe una correlación entre la duración de la tos y los parámetros de inflamación y daño parenquimatoso evidenciado a través de peores puntajes de daño imagenológico, también asociado a una mala evolución clínica y funcional, como se ha observado en estudios de adultos (Tabla 2).

\section{TRATAMIENTO}

El tratamiento se basa, fundamentalmente, en tres pilares:

- Tratar la causa de base (cuando existe un diagnóstico identificado).

- Prevenir y tratar las exacerbaciones respiratorias.

- Facilitar el drenaje de las secreciones de la vía aérea.

El objetivo en el tratamiento del paciente con bronquiectasias no FQ en pediatría consiste, principalmente, en disminuir la progresión de la enfermedad, minimizar las exacerbaciones y evitar las complicaciones. Asimismo, pretende mejorar o mantener la función pulmonar promoviendo un crecimiento y desarrollo adecuados con la mejor calidad de vida posible..$^{35-37}$

Para ello, se cuenta con las siguientes estrategias (Tabla 3):

1. Antibiótico-terapia (en exacerbación y tratamiento crónico. Sistémica e inhalada).

2. Fisioterapia respiratoria.

3. Agentes mucolíticos.

4. Broncodilatadores inhalados.

5. Antiinflamatorios (esteroideos y no esteroideos -AINES-).

6. Inmunizaciones/vacunas.

7. Soporte nutricional.

8. Actividad física.

9. Control del medioambiente.

\section{A. Tratamiento antibiótico en exacerbaciones respiratorias agudas \\ Definición de exacerbación}

Se puede definir "exacerbación" por la presencia de 3 o más de los siguientes síntomas: aumento de la tos, cambios en las características del esputo (aumento del volumen, viscosidad y purulencia), incremento de la disnea, presencia de sibilancias, hemoptisis y/o afectación del estado 
TABla 2. Algoritmo de diagnóstico
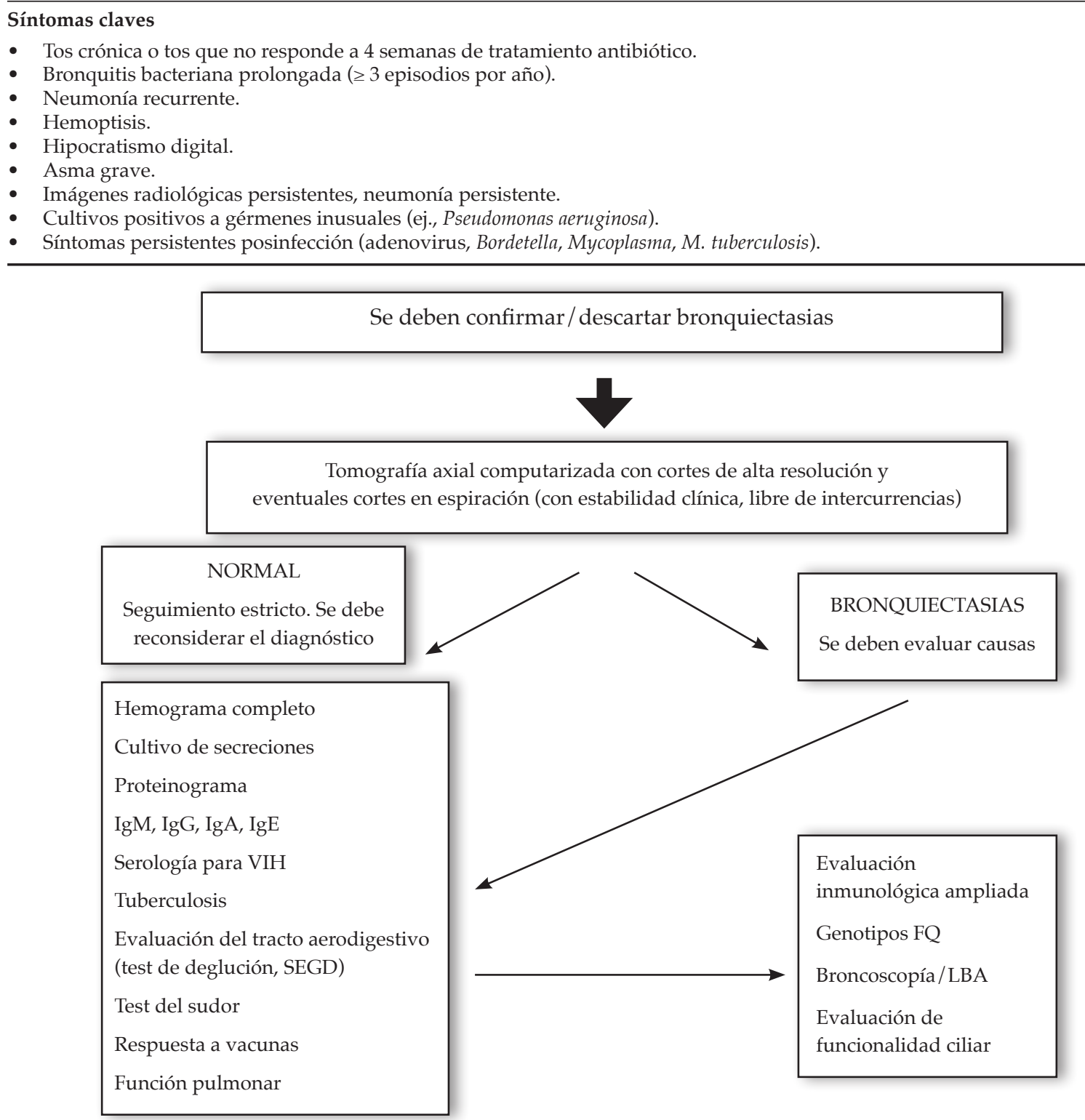

Fuente propia.

IgM: inmunoglobulina M; IgG: inmunoglobulina G; IgA: inmunoglobulina A; IgE: inmunoglobulina E;

VIH: virus de la inmunodeficiencia humana; SEGD: serie esofagogastroduodenal.

TABLA 3. Recomendaciones en bronquiectasias no fibrosis quística ${ }^{11}$

\section{Recomendaciones en el manejo del paciente pediátrico}

A. Identificar cualquier causa subyacente tratable y condiciones asociadas.

B. Diagnóstico inmediato, tratamiento y prevención de exacerbaciones agudas.

C. Manejos nutricionales y psicosociales.

D. Mejorar la higiene de las vías respiratorias.

E. Fomentar la actividad física.

F. Vigilancia periódica de las complicaciones de la bronquiectasia.

G. Educación continua y promoción de medidas generales de salud: evitar el humo del tabaco, otros tóxicos ambientales inhalados.

H. Vacunas completas. 
general (fatiga o fiebre), con deterioro agudo y sostenido por más de 3 días. ${ }^{35}$

Reconocer y tratar precozmente la exacerbación respiratoria es fundamental en el manejo de estos pacientes, ya que su frecuencia y gravedad se relacionan directamente con la caída de la función pulmonar, la calidad de vida y la sobrevida de estos. Se ha evidenciado que la presencia de más de tres exacerbaciones por año aumenta significativamente la morbimortalidad en los pacientes con bronquiectasias no FQ. ${ }^{38}$

\section{Bacteriología}

Es recomendable tomar una muestra microbiológica del esputo, siempre que sea posible, antes de iniciar el tratamiento antibiótico. En los pacientes colaboradores, se solicitará la muestra de esputo. En los niños pequeños $\mathrm{y} / \mathrm{o}$ en aquellos que no puedan expectorar, un hisopado profundo de la faringe tras inducir la tos ha demostrado ser sensible y específico para identificar los patógenos de la vía aérea inferior. ${ }^{39}$

Conocer la bacteriología habitual del paciente con bronquiectasia no FQ mediante el cultivo de esputo permite realizar el monitoreo individual de la microbiología del paciente, que será de gran utilidad para guiar el tratamiento antimicrobiano inicial durante la exacerbación. ${ }^{40}$ Es importante contar con el recuento de colonias del material de cultivo, ya que la "carga bacteriana" se relaciona con el riesgo de exacerbaciones posteriores y con la gravedad de los síntomas respiratorios. ${ }^{41}$

Entre las bacterias más comúnmente aisladas en niños con bronquiectasias no FQ se encuentran, principalmente, Haemophilus influenzae no encapsulado, Streptococcus pneumoniae, Moraxella catarrhalis y Staphylococcus aureus. ${ }^{42,43}$ Menos frecuentemente, se pueden identificar Pseudomonas aeruginosa, Staphylococcus aureus resistente a meticilina, Aspergillus y/o micobacterias no tuberculosas. Estos últimos pueden presentarse, sobre todo, en niños de mayor edad, con enfermedad avanzada y mayor daño pulmonar. ${ }^{44,45}$

Los virus han sido involucrados en la patogénesis de bronquiectasias (sobre todo, adenovirus e influenza) y también pueden desencadenar una exacerbación respiratoria. Un estudio publicado en 2014, que incluyó a 69 niños con bronquiectasias no FQ en seguimiento durante un período prolongado, observó 77 episodios de exacerbaciones, de las cuales el $48 \%$ se asociaron a etiología viral (rinovirus fue el más frecuente, seguido de parainfluenza). ${ }^{46,47}$

\section{Antibióticos}

La terapia con antibióticos es la herramienta más efectiva en la prevención y el tratamiento de la exacerbación respiratoria y de la erradicación de Pseudomonas en pacientes con bronquiectasias no FQ, ya que reduce la carga bacteriana de las vías aéreas inferiores e interrumpe el ciclo de infección e inflamación. La elección del antibiótico deberá guiarse por la gravedad de la exacerbación y por el resultado de la microbiología. Se tienen en cuenta, además, factores propios de los antibióticos (como seguridad, eficacia y facilidad de administración) y del paciente (como edad, comorbilidades, grado de exacerbación, uso reciente de antibióticos, entre otros).

Debido a que los gérmenes más frecuentemente aislados en pediatría son Haemophilus influenzae, S. pneumoniae y Moraxella catarrhalis, en caso de no contar con la bacteriología del paciente, el tratamiento empírico inicial debería cubrir estos patógenos habituales. Existen pocos estudios en pediatría que comparen diferentes regímenes de antibióticos para el tratamiento empírico en las exacerbaciones leves. Recientemente, se publicaron dos estudios: el estudio BEST-1, en el que compararon el uso de amoxicilina-clavulánico vs. placebo y azitromicina vs. placebo. Se observó que ambos esquemas resultaron superiores al placebo en el tiempo de la resolución de las exacerbaciones. El estudio BEST-2, por su parte, comparó el uso de amoxicilina-clavulánico vs. azitromicina como primera línea de tratamiento en las exacerbaciones leves. No encontraron diferencias entre estos dos antibióticos en la resolución de las exacerbaciones ni en los biomarcadores inflamatorios, pero sí en el tiempo de resolución: el tratamiento con amoxicilina-clavulánico fue más corto (10 vs. 14 días). Además, si bien el uso de azitromicina obtuvo mejor adherencia por parte de los pacientes, presentó mayor resistencia bacteriana. ${ }^{48}$

En relación con la duración del tratamiento para la exacerbación respiratoria, habitualmente, se recomienda de 10 a 14 días. Asimismo, algunos pacientes pueden requerir ciclos más prolongados: de 4 a 8 semanas. ${ }^{49}$ Una revisión de Cochrane mostró una significativa reducción en el porcentaje de exacerbaciones y de hospitalización en niños y adultos con bronquiectasias no FQ que habían sido tratados con un curso de antibióticos prolongados (4 o más semanas) durante su última exacerbación. Sin embargo, se observó mayor riesgo de aparición de patógenos emergentes y resistencia a las drogas antimicrobianas. ${ }^{50}$ 


\section{Recomendación para exacerbaciones agudas (Tabla 4)}

- Exacerbaciones leves: amoxicilina/amoxiclavulánico.

- En pacientes con hipersensibilidad a la penicilina: macrólidos (azitromicina).

- En casos graves, falta de respuesta clínica e/o intolerancia a los antibióticos orales, se indicará ampicilina / cefalosporina de segunda o tercera generación, piperacilina/tazobactam.

- Se deben revisar los antibióticos por vía intravenosa a las 48 horas y considerar antibióticos orales cuando sea posible por un ciclo antibiótico total de 7 a 14 días.

- No se recomienda el tratamiento empírico para $P$. aeruginosa si no hubo infección previa o colonización documentada. ${ }^{40,51}$

- En las exacerbaciones desencadenadas por virus, la opinión de expertos recomienda el tratamiento con antibióticos. ${ }^{35}$

- Es importante el manejo individualizado del paciente. Los casos graves deben ser referidos al especialista.

\section{Tratamiento antibiótico en el paciente crónico}

El uso de antibióticos orales en forma crónica continúa siendo controvertido. La mayoría de las guías recomiendan su indicación solo cuando el paciente presenta exacerbaciones frecuentes (más de tres anuales) o caída significativa de su función pulmonar. ${ }^{35,40}$

Los antibióticos que más han sido utilizados de manera prolongada para el tratamiento de las bronquiectasias son los macrólidos. ${ }^{42}$ Entre ellos, la azitromicina es el primero en frecuencia. Los macrólidos tienen propiedades antiinflamatorias e inmunomoduladoras (además de antibacterianas). Son bacteriostáticos para Staphylococcus y Haemophilus, y bactericidas frente a $P$. aeruginosa. Otras ventajas se relacionan con la inhibición de la adherencia bacteriana a las células epiteliales y la disminución en la formación de

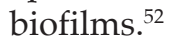

De los estudios sobre el tratamiento a largo plazo con macrólidos en niños con bronquiectasia no FQ, en el más reciente, realizado en Australia y en Nueva Zelandia con niños aborígenes, se les administraron $30 \mathrm{mg} / \mathrm{kg} /$ dosis (máximo de $600 \mathrm{mg}$ ) de azitromicina una vez a la semana durante 1-2 años vs. placebo. Si bien se observó un menor número de exacerbaciones y disminución en los casos de portadores de H. influenzae y

TABLA 4. Recomendaciones para exacerbaciones agudas en pacientes con bronquiectasias no fibrosis quística ${ }^{84}$

\begin{tabular}{|c|c|c|}
\hline & $\begin{array}{c}\text { Exacerbación leve } \\
\text { Vía oral }\end{array}$ & $\begin{array}{l}\text { Exacerbación grave } \\
\text { Vía endovenosa: falta de respuesta clínica y/o } \\
\text { intolerancia a los antibióticos orales }\end{array}$ \\
\hline $\begin{array}{l}\text { Empírico inicial } \\
\text { En pacientes con } \\
\text { hipersensibilidad } \\
\text { a la penicilina }\end{array}$ & $\begin{array}{l}\text { Amoxicilina, amoxicilina/clavulánico, } \\
\text { cefalexina, ciproflaxina } \\
\text { con rescate reciente de Pseudomonas. } \\
\text { Macrólidos (azitromicina). }\end{array}$ & $\begin{array}{c}\text { Ampicilina, amoxicilina / clavulánico, } \\
\text { ampicilina/sulbactam, cefuroxima, } \\
\text { cefotaxima o ceftriaxona, } \\
\text { piperalicina/tazobactam o } \\
\text { ceftazidima + amikacina (si están presentes } \\
\text { Pseudomonas } a \text {. y terapia dual si está colonizado). }\end{array}$ \\
\hline $\begin{array}{l}\text { Haemophilus influenzae } \\
\beta \text {-lactamasa }(-) \\
\beta \text {-lactamasa }(+)\end{array}$ & $\begin{array}{l}\text { Amoxicilina. } \\
\text { Amoxicilina/clavulánico. }\end{array}$ & $\begin{array}{c}\text { Ampicilina. } \\
\text { Ampicilina/sulbactam, } \\
\text { cefuroxima, cefotaxima, ceftriaxona. }\end{array}$ \\
\hline Streptococcus pneumoniae & Amoxicilina. & Ampicilina. \\
\hline Moraxella catarrhalis & $\begin{array}{l}\text { Amoxicilina, } \\
\text { Amoxicilina/clavulánico. }\end{array}$ & $\begin{array}{c}\text { Ampicilina. } \\
\text { Ampicilina/sulbactam, } \\
\text { cefuroxima, cefotaxima, ceftriaxona. }\end{array}$ \\
\hline $\begin{array}{l}\text { Staphylococcus aureus } \\
\text { Staphylococcus aureus } \\
\text { resistente a la meticilina }\end{array}$ & $\begin{array}{l}\text { Cefalexina. } \\
\text { Se debe consultar } \\
\text { al especialista. }\end{array}$ & $\begin{array}{l}\text { Cefalotina. } \\
\text { Se debe consultar } \\
\text { al especialista. }\end{array}$ \\
\hline Pseudomonas aeruginosa & Ciprofloxacina. & $\begin{array}{c}\text { B-lactamasa (piperacilina/tazobactam, } \\
\text { cefotaxima o ceftazidima) } \\
\text { + amikacina (terapia dual si está colonizado). }\end{array}$ \\
\hline $\begin{array}{l}\text { Micobacterias } \\
\text { no tuberculosas }\end{array}$ & $\begin{array}{l}\text { Se debe consultar } \\
\text { al especialista. }\end{array}$ & $\begin{array}{l}\text { Se debe consultar } \\
\text { al especialista. }\end{array}$ \\
\hline
\end{tabular}

* No se recomienda el tratamiento empírico para $P$. aeruginosa si no hubo infección previa o colonización documentada. 
M. catarrhalis, se registró un aumento en la resistencia bacteriana a los macrólidos..$^{53}$

No se recomiendan las dosis elevadas (para minimizar los efectos adversos). El tratamiento no debe exceder los 12-24 meses (con seguimiento estricto clínico y bacteriológico). Asimismo, antes de iniciar el tratamiento con macrólidos, es importante verificar que no haya presencia de micobacterias no tuberculosas en el esputo. Tampoco se recomienda su uso en pacientes con QTc prolongado en el electrocardiograma ni en pacientes con audición alterada (por el riesgo de daño coclear en individuos susceptibles). Se recomienda realizar previamente una interconsulta con el especialista.

- Por lo anteriormente expuesto, y dadas las preocupaciones por los potenciales efectos adversos del tratamiento con macrólidos a largo plazo, las guías recomiendan un uso racional de estos, identificar a los pacientes que se beneficiarían con su uso, considerar la dosis y la duración en cada caso en particular. Además, realizar previamente una interconsulta con el especialista. Véase el Anexo.

Otros antibióticos orales, como clotrimazol, tetraciclinas o amoxicilina, han sido usados para la prevención de exacerbaciones, pero no existen evidencias que avalen su uso en forma crónica en pacientes pediátricos. ${ }^{42}$

\section{Antibióticos inhalados}

Los antibióticos inhalados presentan una eficacia clara en los pacientes con bronquiectasias en FQ, no así en los pacientes con bronquiectasias no FQ. Estos tienen una adecuada concentración de droga en la vía aérea baja con mínima toxicidad sistémica, lo que hace que tengan un rol importante en el manejo de la colonización

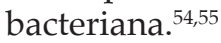

Un reciente metaanálisis de ocho trabajos con la participación de 590 adultos estables con infección bronquial crónica que recibieron aminoglucósidos inhalados por un período de 1-12 meses mostró que los antibióticos inhalados eran más efectivos que un placebo en la disminución de la carga bacteriana en esputo y en la reducción de las exacerbaciones, pero no redujeron significativamente el ingreso hospitalario por exacerbación, calidad de vida ni mejoría en la función pulmonar. La carga bacteriana reaparecía en el esputo una vez que se discontinuaba el tratamiento inhalado. ${ }^{56}$ Como efecto indeseable, un $10 \%$ de los pacientes presentaron broncoespasmo. Estos resultados reflejan la heterogeneidad de las bronquiectasias.

Si bien la tobramicina inhalada mostró eficacia en reducir la concentración de Pseudomonas y mejoría del volumen espiratorio forzado en el primer segundo (VEF1) en pacientes con FQ, hay pocos registros de su uso en pacientes pediátricos con bronquiectasias no FQ. Lamentablemente, no se cuenta con ensayos clínicos aleatorizados en la población pediátrica. ${ }^{57}$ Los expertos recomiendan evaluar el grado de compromiso, la disponibilidad de la droga, el costo y los efectos adversos antes de indicarla.

En las guías británicas, se acordó el uso de antibióticos inhalados solo en pacientes pediátricos que presentaran exacerbaciones frecuentes (más de 3 por año), falta de respuesta con el uso de antibióticos orales crónicos y en los pacientes colonizados por Pseudomonas aeruginosa. ${ }^{35}$

\section{Recomendación de antibióticos prolongados con la interconsulta previa con el especialista:}

- Azitromicina por vía oral de 6 a 24 meses solo en pacientes con más de tres exacerbaciones anuales o 2 internaciones en un año.

- Antibióticos inhalados. Tobramicina o colistimetato de sodio solo en pacientes con infección por Pseudomonas o más de tres exacerbaciones anuales o cuando los macrólidos estén contraindicados.

- Se recomienda la lectura del esquema antibiótico sugerido, al final del documento.

\section{B. Fisioterapia respiratoria}

Si bien es escasa la evidencia en pediatría y la mayoría de las experiencias en niños están basadas en estudios de pacientes con FQ, la fisioterapia respiratoria en pacientes con bronquiectasias no FQ mejora el aclaramiento mucociliar y facilita el drenaje de secreciones de las vías aéreas inferiores. ${ }^{58,59}$ Existen diferentes técnicas kinésicas, como el drenaje postural, ejercicios de aumento del flujo ventilatorio, de expansión torácica, mediante el juego con pelotas, con cama elástica o con dispositivos específicos (Flutter, Triflow, Acapella, entre otros), con lo cual se busca generar vibración en la vía aérea y la movilización de secreciones. Las técnicas de respiración complementan las maniobras que tienen como objetivo la expectoración de secreciones. Los factores por tener en cuenta para 
seleccionar las diferentes técnicas tienen que ver con la edad del niño, el nivel de colaboración, la adherencia, la disponibilidad y el costo. ${ }^{60}$

- Se recomienda la fisioterapia respiratoria en todos los pacientes con bronquiectasias no FQ en forma diaria en el hogar. Se debe entrenar al niño y a los familiares, y supervisar periódicamente los ejercicios indicados. En caso de presentar una exacerbación respiratoria, se debe incrementar la rutina diaria.

\section{Agentes mucolíticos}

Los agentes mucolíticos representan otro recurso en el manejo de los pacientes con bronquiectasias, ya que mejoran el aclaramiento mucociliar y facilitan la expectoración del moco. La evidencia actual se refiere, en general, a pacientes adultos con FQ y en bronquiectasias no FQ. ${ }^{61,62}$

\section{Solución salina hipertónica}

Es el mucolítico más utilizado en bronquiectasias no FQ. En los pocos estudios publicados en pediatría, muestran poca efectividad en pacientes estables. ${ }^{63}$ Kellet y col. demostraron, en pacientes con exacerbaciones frecuentes, que la nebulización con la solución salina hipertónica usada junto con la kinesioterapia redujo la viscosidad del esputo en pacientes con bronquiectasias no FQ. ${ }^{64,65}$

- La solución salina hipertónica no estaría indicada en forma rutinaria a todos los pacientes. Se podría considerar su uso en pacientes con exacerbaciones respiratorias frecuentes, con la consulta previa con el equipo tratante. Se debe considerar la posibilidad de irritación de la vía aérea y obstrucción bronquial.

\section{Manitol}

No se recomienda su uso en la población pediátrica. Existen evidencias en Cochrane sobre el uso del manitol (400 mg inhalado dos veces por día durante 12 meses) en pacientes con bronquiectasias no FQ en adultos. Estos observaron una mejoría en la calidad de vida y en retrasar el tiempo de la primera exacerbación, pero no disminuyó la tasa de exacerbaciones. No se cuenta con estudios en la población pediátrica. ${ }^{66,67}$

\section{Desoxiribonucleasa sintética obtenida por tecnología recombinante humana (rhDNasa)}

No se recomienda su uso en niños con bronquiectasias no FQ. No se cuenta con estudios en la población pediátrica y está contraindicado en adultos, ya que se reportó un incremento de las exacerbaciones y mayor trabajo respiratorio en un estudio con bronquiectasias no FQ. ${ }^{68}$

\section{Nuevos agentes mucolíticos}

La N-acetilcisteína inhalada no se recomienda en pediatría. Si bien disminuye la viscosidad del moco de las vías respiratorias y ha demostrado ser eficaz en la inhibición de la formación de biopelículas y en la reducción de la viabilidad bacteriana por disminución del biofilm durante el tratamiento antibiótico (Klebsiella-Pseudomonas), la efectividad en niños con bronquiectasia fue insuficiente.

La erdosteína es un nuevo mucolítico similar a la N-acetilcisteína con menos efectos tóxicos sistémicos y ha demostrado buenos resultados en pacientes adultos con bronquitis crónica y enfermedad pulmonar obstructiva crónica (EPOC). Se requieren estudios en pediatría. ${ }^{69}$

\section{Broncodilatadores}

Algunos pacientes con bronquiectasias no FQ pueden presentar hiperreactividad bronquial y obstrucción bronquial, por lo que los B2 agonistas adrenérgicos con o sin corticoides inhalados pueden ser efectivos. ${ }^{70,71}$ Una revisión de Cochrane evaluó, en niños y adultos, el uso crónico de corticoides inhalados más broncodilatadores de acción prologada (long-acting beta-agonists; $L A B A$, por sus siglas en inglés) comparado con un grupo control (placebo, sin tratamiento y uso de corticoide solo) en pacientes con bronquiectasias no FQ (niños y adultos). Concluyó que el uso de corticoide inhalado más $L A B A$ fue más efectivo que los corticoides en altas dosis. Se observó una mejoría clínica en menos días de tos y disnea. No modificó la tasa de hospitalización ni mejoró la función pulmonar..$^{70,72,73}$

- Se recomienda el uso de salbutamol en pacientes con hiperreactividad confirmada, precediendo o asociado a la solución hipertónica. Los corticoides inhalados solos o asociados a $L A B A$ se indicarán solo en los pacientes con diagnóstico de asma concomitante y no de forma rutinaria. 


\section{E. Nuevas terapias \\ Antiinflamatorios}

AINES en bronquiectasias no FQ: Se supone un efecto antiinflamatorio. De acuerdo con una revisión reciente de Cochrane, no hay evidencia para recomendar el uso de los AINES en bronquiectasias no FQ. ${ }^{74}$

Tratamientos en el sistema inmunitario y neutrófilos: Los neutrófilos son las células principales en la patogénesis de las bronquiectasias. Existen diferentes terapias que regulan la producción de neutrófilos y retrasan la progresión de las bronquiectasias, como el inhibidor de la elastasa, captesina C y CXCR2, otras terapias inmunomoduladoras (vit. D, factor estimulante de colonias y granulocitos, inhibidores de la fosfodiesterasa 4 y estatina). No hay evidencia suficiente para indicar su uso. ${ }^{73,74}$

\section{F. Inmunizaciones}

Los niños con diagnóstico de bronquiectasias deben recibir todas las vacunas correspondientes al calendario nacional. Deberán recibir, además, la protección adicional con vacuna antiinfluenza estacional y vacuna antineumocóccica tal cual lo describen las normas descritas en el plan nacional de inmunizaciones.

Existen avanzadas investigaciones en el uso de la vacuna anti Haemophilus influenzae no tipificable, anti Pseudomonas y anti virus respiratorio sincicial (VRS), que, en un futuro no muy lejano, aparecerán como opciones preventivas. ${ }^{75}$

\section{G. Broncoscopía}

No está indicada en forma rutinaria. Puede ser necesaria solo en algunos casos: cuando se sospeche un cuerpo extraño o alteraciones estructurales congénitas, como traqueobroncomalacia, fístula traqueoesofágica, etc. También puede ser necesaria en algunos niños con enfermedad grave y localizada que no respondan al tratamiento o si los cultivos de esputo son negativos y se deben proporcionar muestras para microbiología, citología o biopsia, o si la TACAR sugiere infección por micobacterias no tuberculosas y no se logra el rescate bacteriológico a través de métodos convencionales de recolección. ${ }^{35}$ El lavado broncoalveolar (LBA), procedimiento que, generalmente, no se realiza de rutina, es una técnica invasiva, con disponibilidad limitada en pediatría, que se reserva solo para los casos en la etapa de diagnóstico inicial y / o ante la falta de respuesta al tratamiento e incapacidad de producir esputo o ante reiterados cultivos de esputo negativos y persistencia de la clínica. ${ }^{35}$

\section{COMPLICACIONES \\ Hemoptisis}

Constituye una de las complicaciones graves de las bronquiectasias no FQ. Se produce, en general, como consecuencia del daño generado en las paredes de las vías aéreas sometidas al ciclo vicioso inflamación/infección. En algunos sitios del parénquima pulmonar dañado, sobre todo, en aquellos con baja oxigenación, se producen áreas altamente irrigadas por vasos de neoformación provenientes de la circulación sistémica (arterias bronquiales, ramas colaterales de la aorta, arteria mamaria interna, etc.), que, al romperse, vuelcan su contenido de manera muy profusa por la alta arborización y la elevada presión del circuito sistémico al que pertenecen. ${ }^{76}$

Aquellos eventos en los que el esputo sea hemoptoico (presente estrías sanguinolentas) o el volumen de sangre sea mínimo (menos de $10 \mathrm{ml} / 24 \mathrm{~h}$ ), el manejo puede ser ambulatorio con cobertura antibiótica y pautas estrictas de alarma. Existe escasa literatura sobre el manejo de la hemoptisis en niños no FQ; en general, se siguen las normativas de FQ. La prioridad es mantener despejada la vía aérea, optimizar la oxigenación y estabilizar el estado hemodinámico, seguido de la embolización de la arteria bronquial o el área comprometida. Se ha demostrado que la embolización de la arteria bronquial en forma percutánea es un método seguro y efectivo. ${ }^{35,76}$ En la hemoptisis grave (más de $240 \mathrm{ml}$ de sangre en 24 h o $100 \mathrm{ml}$ / día/ 5 días) y/o progresión del cuadro y si se observan signos de deterioro clínico y/o de laboratorio, el manejo debe ser en internación para el monitoreo estricto y bajo el cuidado de un grupo multidisciplinario, que incluya al neumonólogo, radiólogo intervencionista con experiencia en tratamientos de embolización selectiva y cirujanos torácicos.

\section{Cirugía}

Los procedimientos quirúrgicos en niños con bronquiectasias no FQ deben ser cuidadosamente evaluados por el equipo interdisciplinario. Solo se plantea esta posibilidad si las lesiones están bien localizadas y limitadas a un solo lóbulo y/o segmento que genere síntomas graves (falla de crecimiento, infecciones recurrentes que no responden a las terapias convencionales o hemoptisis grave y recurrente, mala calidad de vida del paciente, halitosis, broncorrea y recaídas frecuentes que requieren tratamientos prolongados). ${ }^{77}$

El abordaje quirúrgico debe ser realizado por 
personal entrenado en cirugías de tórax. Aun en los mejores centros, la tasa de mortalidad alcanza el 5,6\%. La utilización de técnicas mínimamente invasivas (laparoscopía) constituye una alternativa. ${ }^{21,78}$

\section{MONITOREO}

Tiene como objetivos identificar complicaciones, prevenir exacerbaciones y ayudar en la toma de decisiones de tratamiento. Los niños con bronquiectasias no FQ deben ser evaluados en forma periódica con una frecuencia que variará según el grado de compromiso clínico. Se sugiere una frecuencia mínima de 3 o 4 veces por año, teniendo en cuenta factores, como la adherencia al tratamiento. Idealmente, debería ser realizado por el neumonólogo y con asistencia de un equipo multidisciplinario. ${ }^{28,30}$

Las evaluaciones deberán contemplar lo siguiente:

a. El crecimiento, el desarrollo y el estado nutricional son indicadores clínicos importantes de gravedad. En una cohorte de Londres, de 20 niños con bronquiectasias no FQ con VEF1 $<80 \%$ del predicho, se asociaron con un índice de masa corporal (IMC) más bajo. ${ }^{30,31}$

b. El control de signos y síntomas relacionados con las exacerbaciones posibilita un tratamiento más temprano y permite reducir la progresión de la enfermedad. Para eso, es necesario establecer el estado basal del paciente $y$, a partir de ello, detectar signos y síntomas, como aumento de la disnea, intolerancia al ejercicio, aumento de la tos y características del esputo.

En los niños, un cambio en la calidad de la tos (de seca a húmeda) y / o la frecuencia/ gravedad, así como la falta de progresión de peso, son los marcadores más importantes de exacerbación. ${ }^{22,35}$ Tener en cuenta las características del esputo (color y volumen) también es útil, ya que el color puede predecir una infección bacteriana y está asociado con inflamación bronquial. El cultivo del esputo debe ser obtenido regularmente y ante exacerbaciones. . $22,35^{2}$

c. Función pulmonar: todos los pacientes deberán tener una medición inicial de la función pulmonar a través de una espirometría (en niños $>$ de 4 a 5 años en la que se logre técnica y colaboración). La frecuencia dependerá del estado clínico y del grado de compromiso de la función pulmonar.
La función pulmonar es un marcador poco sensible para el diagnóstico y el seguimiento de pacientes con bronquiectasias no FQ en pediatría. La espirometría es el estudio más frecuentemente utilizado, que puede complementarse con la medición de volúmenes pulmonares. La función pulmonar puede ser normal aun ante cambios radiológicos evidentes. ${ }^{30,79}$ En general, se puede observar un compromiso obstructivo y, en ocasiones, mixto de la función pulmonar. Se debe considerar la evaluación de la respuesta broncodilatadora. Dentro de las evaluaciones funcionales, se debe incluir el test de marcha o de la caminata de 6 minutos cada 6 o 12 meses según la evolución clínica. $^{80}$

d. La decisión de repetir imágenes depende del equipo tratante. La radiografía de tórax es poco sensible y no está recomendada para el monitoreo. ${ }^{81}$ La TACAR de tórax conlleva el riesgo de exposición a la radiación, por lo que su realización durante el monitoreo solo se reserva para pacientes en quienes se sospecha deterioro clínico y / o complicaciones y cuando las decisiones pueden modificar las conductas terapéuticas.

Tratándose de una población pediátrica, se recomienda la realización en centros con experiencia en atención de niños, en lo posible, sin sedación o anestesia, en condiciones de estabilidad clínica, sin intercurrencias (no antes de 4 a 6 semanas después de una exacerbación). La repetición de los estudios por imágenes en niños estables queda a criterio del equipo tratante o del especialista. La resonancia magnética de tórax, actualmente, solo se utiliza en investigación y parece prometer una futura modalidad de imagen en el estudio y monitoreo de bronquiectasias no FQ., 2,11,22,82

e. Otras pruebas estarán sujetas en cada caso particular y su regularidad será decisión del equipo tratante, por ejemplo: el test de ejercicio, el índice de aclaramiento mucociliar (lung clearance index; LCI, por sus siglas en inglés) y estudios de laboratorio, como medición de óxido nítrico nasal, cepillado nasal/bronquial, pruebas moleculares para el estudio de DCP..$^{83}$ Marcadores biológicos, como la medición de elastasa en el esputo, podrían ser herramientas futuras que, actualmente, siguen en investigación. ${ }^{11,22}$ 


\section{CONCLUSIONES}

Las bronquiectasias se encuentran dentro del espectro de enfermedad pulmonar crónica caracterizada por la dilatación bronquial progresiva y, a menudo, irreversible, causada por cambios estructurales en la pared bronquial e inflamación crónica de las vías respiratorias. Puede iniciarse por una afección predisponente, como es la BBP (hipótesis de investigaciones más recientes). En ambas situaciones, el síntoma cardinal es la tos crónica persistente húmeda/ productiva, que debe alertar para realizar una intervención oportuna e interrumpir el ciclo de inflamación, infección y daño de la vía aérea.

La prevalencia de las bronquiectasias en los últimos años se ha incrementado gracias al reconocimiento y mejor diagnóstico a través de estudios complementarios, como es la TACAR de tórax. La etiología, epidemiología, determinantes geográficos y ambientales, así como comprender los fenotipos de la enfermedad, son necesarios para adoptar intervenciones específicas y adecuadas.

Si bien los enfoques terapéuticos actuales para el manejo de bronquiectasias parecen ser efectivos, existen pocos estudios clínicos aleatorizados en la población pediátrica y, en el futuro, se necesita avanzar en este punto. Actualmente, la atención multidisciplinaria, el reconocimiento y el tratamiento precoz de las exacerbaciones basadas en la microbiología, la depuración de las vías respiratorias y las acciones preventivas son los pilares del tratamiento y han demostrado clara utilidad. El futuro cercano parece prometer un enfoque más individualizado para la evaluación y el tratamiento de pacientes con bronquiectasias no $F Q$, con una medicina personalizada que utilice análisis genéticos, biomarcadores locales y sistémicos para estratificar a los pacientes en términos de pronóstico y terapia.

\section{REFERENCIAS}

1. Chang AB, Bell SC, Torzillo PJ, King PT, et al. Chronic suppurative lung disease and bronchiectasis in children and adults in Australia and New Zealand thoracic society of Australia and New Zealand guidelines. Med J Aust. 2015; 202(1):21-3.

2. Gallucci M, Di Palmo E, Bertelli L, Camela F, et al. A pediatric disease to keep in mind: diagnostic tools and management of bronchiectasis in pediatric age. Ital J Pediatr. 2017; 43(1):117.

3. Santamaria F, Montella S, Pifferi M, Ragazzo V, et al. A descriptive study of non-cystic fibrosis bronchiectasis in a pediatric population from central and southern Italy. Respiration. 2009; 77(2):160-5.

4. Eastham KM, Fall AJ, Mitchell L, Spencer DA. The need to redefine non cystic fibrosis bronchiectasis in childhood.
Thorax. 2004; 59(4):324-7.

5. Kapur N, Karadag B. Differences and similarities in noncystic fibrosis bronchiectasis between developing and affluent countries. Pediatr Respir Rev. 2011; 12(2):91-6.

6. Twiss J, Metcalfe R, Edwards E, Byrnes C. New Zealand national incidence of bronchiectasis "too high" for a developed country. Arch Dis Child. 2005; 90(7):737-40.

7. Nathan AM, Muthusamy A, Thavagnanam S, Hashim A, et al. Chronic suppurative lung disease in a developing country: impact on child and parent. Pediatr Pulmonol. 2014; 49(5):35-40.

8. Guran T, Turan S, Karadag B, Ersu R, et al. Bone mineral density in children with non-cystic fibrosis bronchiectasis. Respiration 2008; 75(4)432-6.

9. Martínez Chamorro MJ. Bronquiectasias no asociadas a fibrosis quística. Diciembre 2016. [Acceso: 5 de agosto de 2020]. Disponible en: https://www.aepap.org/ sites / default / files / documento / archivos-adjuntos / bronquiectasias_fin.pdf.

10. Cole PJ. Inflammation: a two-edged sword-the model of bronchiectasis. Eur J Respir Dis Suppl. 1986; 147:6-15.

11. Goyal V, Grimwood K, Marchant J, Masters IB, et al. Pediatric bronchiectasis: no longer an orphan disease. Pediatr Pulmonol. 2016; 51(5):450-69.

12. Gould CM, Freeman AF, Olivier KN. Genetic causes of bronchiectasis. Clin Chest Med. 2012; 33(2):249-63.

13. Gaga M, Bentley AM, Humbert M, Barkans J, et al. Increases in CD4p T lymphocytes, macrophages, neutrophils and interleukin 8 positive cells in the airways of patients with bronchiectasis. Thorax. 1998; 53(8):685-91.

14. Devaraj A, Wells AU, Meister MG, Loebinger MR, et al. Pulmonary hypertension in patients with bronchiectasis: prognostic significance of CT signs. Am J Roentgenol. 2011; 196(6):1300-4.

15. Alzeer AH, Al-Mobeirek AF, Al-Otair HA, Elzamzamy UA, et al. Right and left ventricular function and pulmonary artery pressure in patients with bronchiectasis. Chest. 2008; 133(2):468-73.

16. Chang AB, Masel JP, Boyce NC, Wheaton G, et al. NonCF bronchiectasis: clinical and HRCT evaluation. Pediatr Pulmonol. 2003; 35(6):477-83.

17. Chang AB, Upham JW, Masters IB, Redding GR, et al. Protracted bacterial bronchitis: The last decade and the road ahead. Pediatri Pulmonol. 2016; 51(3):225-42.

18. Goyal V, Grimwood K, Marchant J, Masters IB, et al. Does failed chronic wet cough response to antibiotics predict bronchiectasis? Arch Dis Child. 2014; 99(6):522-5.

19. Chang AB, Redding GJ, Everard ML. Chronic wet cough: Protracted bronchitis, chronic suppurative lung disease and bronchiectasis. Pediatr Pulmonol. 2008; 43(6):519-31.

20. Wurzel DF, Marchant JM, Yerkovich ST, Upham JW, et al. Prospective characterization of protracted bacterial bronchitis in children. Chest. 2014; 145(6):1271-8.

21. Wu J, Chang A, Wurzel F. Contemporary management of bronchiectasis in children. Expert Rev Respir Med. 2019; 13(10):969-79.

22. Chang AB, Bush A, Grimwood K. Bronchiectasis in children: diagnosis and treatment. Lancet. 2018; 392(10150):866-79.

23. Peng K, Mirra V, Chang A, Santamaria F. Editorial: Chronic Suppurative lung disease and Bronchiectasis in Children and adolescents. Front Pediatr. 2017; 5:196.

24. Chalmers JD, Crichton M, Goeminne PC, Loebinger M, et al. The European Multicenter Bronchiectasis Audit and Research Collaboration (EMBARC): experiences from a successful ERS Clinical Research Collaboration. Breathe (Sheff). 2017; 13(3):180-92. 
25. Brower KS, Del Vecchio MT, Aronoff S. The etiologies of non-CF bronchiectasis in childhood: a systematic review of 989 subjects. BMC Pediatr. 2014; 14:4.

26. Murtagh P, González Pena H, Castaños C, Pinchak MC, et al. Bronquiectasias en la infancia. Arch Pediatr Urug. 2003; 74:3:166-75.

27. Li A, Sonnappa S, Lex C, Wong E, et al. Non-CF bronchiectasis: does knowing the etiology lead to changes in management? Eur Respir J. 2005; 26(1):8-14.

28. Gupta AK, Lodha R, Kabra SK. Non Cystic Fibrosis Bronchiectasis. Indian J Pediatr. 2015; 82(10):938-44.

29. Horani A, Brody SL, Ferkol TW. Picking up speed: advances in the genetics of primary ciliary dyskinesia. Pediatr Res. 2014; 75(1-2):158-64.

30. Navaratnam V, Forrester DL, Pen Eg K, Chang AB. Paediatric and adult bronchiectasis: Monitoring, crossinfection, role of multidisciplinary teams and selfmanagement plans. Respirology. 2019; 24(2):115-26.

31. McCallum GB, Binks MJ. The epidemiology of chronic suppurative lung disease and bronchiectasis in children and adolescents. Front Pediatr. 2017; 5:27.

32. McCallum GB, Chatfield MD, Morris PS, Chang AB. Outcomes of risk factors of Indigenous infants hospitalized with bronchiolitis. Pediatr Pulmonol. 2016; 51(6):613-23.

33. KapurN, MaselJP, WatsonD, Masters I, etal. Bronchoarterial ratio on high resolution $\mathrm{CT}$ scan of the chest in children without pulmonary pathology-need to redefine bronchial dilatation. Chest. 2011; 139(6):1445-50.

34. Long FR, Williams RS, Castile RG. Structural airway abnormalities in infants and young children with cystic fibrosis. J Pediatr. 2004; 144(2):154-61.

35. Pasteur MC, Bilton D, Hill AT, British Thoracic Society Bronchiectasis non-CF Guideline Group. British Thoracic Society guideline for non-CF bronchiectasis. Thorax. 2010; 65(Suppl 1):i1-58.

36. Oliva Hernández C, Suárez López de Vergara RG, Galván Fernández C, Marrero Pérez CL. Atelectasia. Bronquiectasias. Protocolos Diagnósticos Terapéuticos de la AEP. Neumología. 2009:9-24. [Acceso: 26 de septiembre 2016]. Disponible: https: / / www.aeped.es / sites/default / files/documentos/1_4.pdf.

37. Grover A, Joshi A. An overview of chronic disease models: a systematic literature review. Glob J Health Sci. 2014;7(2):21027.

38. Kapur N, Masters IB, Chang AB. Longitudinal growth and lung function in pediatric non-cystic fibrosis bronchiectasis. Chest. 2010; 138(1):158-64.

39. Fakhoury K, Kanu A. Management of bronchiectasis in children without cystic fibrosis. In UpToDate. Rose BD (ed.). Waltham, MA: UpToDate; 2005. [Acceso: 7 de junio de 2016]. Disponible en: https://www.uptodate.com/ contents / management-of-bronchiectasis-in-childrenwithout-cystic-fibrosis.

40. Chang AB, Bell SC, Byrnes CA, Grimwood K, et al. Chronic suppurative lung disease (CSLD) in children and adults in Australian and New Zealand. Med J Aust. 2010; 193(6):35665.

41. Angrill J, Agusti C, De Celis R, Filella X, et al. Bronchial inflammation and colonization in patients with clinically stable bronchiectasis. Am J Respir Crit Care Med. 2001; 164(9):1628-32.

42. Grimwood K, BellSC, Chang AB. Antimicrobial treatmentof non-cystic fibrosis bronchiectasis. Expert Rev Anti Infect Ther. 2014; 12(10):1277-96.

43. Chang AB, Boyce NC, Masters IB, Torzillo PJ, et al. Bronchoscopic findings in children with non-cystic fibrosis chronic suppurative lung disease. Thorax. 2002; 57(11):9358.
44. Kapur N, Grimwood K, Masters IB, Morris PS, et al. Lower airway microbiology and cellularity in children with newly diagnosed non-CF bronchiectasis. Pediatr Pulmonol. 2012; 47(3):300-7.

45. Pavord ID, Beasley R, Agusti A, Anderson GP, et al. After asthma: redefining airways diseases. Lancet. 2018; 391(10118):350-400.

46. Kapur N, Mackay IM, Sloots TP, Masters IB, et al. Respiratory viruses in exacerbations of non-cystic fibrosis bronchiectasis in children. Arch Dis Child. 2014; 99(8):74953.

47. Wurzel DF, Mackay IM, Marchant JM, Wang CYT, et al. Adenovirus species Cis associated with chronicsuppurative lung diseases in children. Clin Infect Dis. 2014; 591(1):34-40.

48. Goyal V, Grimwood K, Byrnes CA, Morris PS, et al. Amoxicillin-clavulanate versus azithromycin for respiratory exacerbations in children with bronchiectasis (BEST-2): a multicentre, double-blind, non-inferiority, randomised controlled trial. Lancet. 2018; 392(10154):11971206.

49. Evans DJ, Bara AI, Greenstone M. Prolonged antibiotics for purulent bronchiectasis in children and adults. Cochrane Database Syst Rev. 2015; (2):CD001392.

50. Hnin K, Nguyen C, Carson KV, Evans DJ, et al. Prolonged antibiotics for non-cystic fibrosis bronchiectasis in children and adults. Cochrane Database Syst Rev. 2015; 2015(8):CD001392.

51. Chang AB, Byrnes CA, Everard ML. Diagnosing and preventing chronic suppurative lung disease (CSLD) and bronchiectasis. Paediatr Respir Rev. 2011; (12)2:97-103.

52. Zarogoulidis P, Papanas N, Kioumis I, Chatzaki E, et al. Macrolides: from in vitro anti-inflammatory and immunomodulatory properties to clinical practice in respiratory diseases. Eur J Clin Pharmacol. 2012; 68(5):479503.

53. Valery PC, Morris PS, Byrnes CA, Grimwood K, et al. Longterm azithromycin for Indigenous children with non-cysticfibrosis bronchiectasis or chronic suppurative lung disease (Bronchiectasis Intervention Study): a multicentre, doubleblind, randomised controlled trial. Lancet Respir Med.2013; 1(8):610-20.

54. Grimwood K, Chang AB. A new dawn: inhaled antibiotics for patients with bronchiectasis. Lancet Respir Med. 2019; 7(3):188-9.

55. Chotirmall SH, Chalmers JD. RESPIRE: breathing new life into bronchiectasis. Eur Respir J. 2018; 51(1):1702444.

56. Monteiro Brodt A, Stovold E, Zhang L. Inhaled antibiotics for stable non-cystic fibrosis bronchiectasis: a systematic review. Eur Respir J. 2014; 44(2):382-93.

57. Ramsey BW, Pepe MS, QuanJM, Otto KL, et al. Intermittent administration of inhaled tobramycin in patients with cystic fibrosis. Cystic fibrosis inhaled Tobramycin study group. N Engl J Med. 1999; 340(1):23-30.

58. Snijders D, Fernandez Dominguez B, Calgaro S, Bertozzi I, et al. Mucociliary clearance techniques for treating non-cystic fibrosis bronchiectasis: is there evidence? Int $J$ Immunopathol Pharmacol. 2015; 28(2):150-9.

59. Lee AL, Burge AT, Holland AE. Airway clearance techniques for bronchiectasis. Cochrane Database Syst Rev. 2015; 2015(11):CD008351.

60. Lee AL, Burge AT, Holland AE. Positive expiratory pressure therapy versus other airway clearance techniques for bronchiectasis. Cochrane Database Syst Rev. 2017; 9(9):CD011699.

61. Kellett F, Robert NM. Nebulised 7\% hypertonic saline improves lung function and quality of life in bronchiectasis. Respir Med. 2011; 105(12):1831-5.

62. Nicolson $\mathrm{CH}$, Stirling RG, Borg BM, Button BM, et al. The 
long-term effect of inhaled hypertonic saline $6 \%$ in non cystic fibrosis bronchiectasis. Respir Med.2012; 106(5):661-7.

63. Herrero-Cortina B, Alcaraz V, Vilaró J, Torres A, et al. Impact of Hypertonic Saline Solutions on Sputum Expectoration and Their Safety Profile in Patients with Bronchiectasis: A Randomized Crossover Trial. J Aerosol Med Pulm Drug Deliv. 2018; 31(5):281-9.

64. Kellett F, Redfern J, Niven RM. Evaluation of nebulised hypertonic saline (7\%) as an adjunct to physiotherapy in patients with stable bronchiectasis. Respir Med. 2005; 99(1):27-31.

65. Máiz L, Girón RM, Prats E, Clemente MG, et al. Addition of hyaluronic acid improves tolerance to $7 \%$ hypertonic saline solution in bronchiectasis patients. Ther Adv Respir Dis. 2018; 12:1753466618787385.

66. Bilton D, Tino G, Barker AF, Chambers DC, et al. Study investigators. Inhaled mannitol for non-cystic fibrosis bronchiectasis: a randomized, controlled trial. Thorax. 2014; 69(12):1073-9.

67. Daviskas E, Anderson SD, Gomes K, Briffa P, et al. Inhaled mannitol for the treatment of mucociliary dysfunction in patients with bronchiectasis: effect on lung function, health status and sputum. Respirology. 2005; 10(1):46-56.

68. O'Donnell AE, Barker AF, Ilowite JS, Fick RB. Treatment of idiopathic bronchiectasis with aerosolized recombinant human DNase I. rhDNase Study Group. Chest. 1998; 113(5):1329-34.

69. Cazzola M, Floriani I, Page CP. The therapeutic efficacy of erdosteine in the treatment of chronic obstructive bronchitis: a meta-analysis of individual patient data. Pulm Pharmacol Ther. 2010; 23(2):135-44.

70. Kapur N, Bell S, Kolbe J, Chang AB. Inhaled steroids for bronchiectasis. Cochrane Database Syst Rev. 2009; (1):CD000996.

71. Goyal V, Chang AB. Combination inhaled corticosteroids and long-acting beta2-agonists for children and adults with bronchiectasis. Cochrane Database Syst Rev. 2014; 2014(6):CD010327.

72. Wurzel DF, Chang AB. An update on pediatric bronchiectasis. Expert Rev Respir Med. 2017; 11(7):517-32.

73. Pizzutto SJ, Upham JW, Yerkovich ST, Chang AB. Inhaled non-steroid anti-inflammatories for children and adults with bronchiectasis. Cochrane Database Syst Rev. 2016; (1):CD007525.

74. Chalmers JD, ChotirmallSH. Bronchiectasis: new therapies and new perspectives. Lancet Respir Med. 2018; 6(9):715-26.

75. Hare KM, Smith-Vaughan HC, Leach AJ, Pizzutto SJ, et al. Reduced nontypeable Haemophilus influenzae lower airway infection in children with chronic endobronchial suppuration vaccinated with the 10 -valent pneumococcal H. influenzae protein D conjugate vaccine. Vaccine. 2018; 36(13):1736-42.

76. Hill AT, Sullivan AL, Chalmers JD, De Soyza A, et al. British Thoracic Society Guideline for bronchiectasis in adults. Thorax. 2019; 74(Suppl 1):1-69.

77. Fan LC, Liang S, Lu HW, Fei K, et al. Efficiency and safety of surgical intervention to patients with Non-Cystic Fibrosis bronchiectasis: a meta-analysis. Sci Rep. 2015; 5:17382.

78. Farrell PM, White TB, Ren CL, Hempstead SE, et al. Diagnosis of Cystic Fibrosis: Consensus Guidelines from the Cystic Fibrosis Foundation. J Pediatr. 2017; 181S:S4-15. e1.

79. Bastardo CM, Sonnappa S, Stanojevic S, Navarro A, et al. Non-cystic fibrosis bronchiectasis in childhood: longitudinal growth and lung function. Thorax. 2009; 64(3):246-51.

80. Hsieh MH, Fang YF, Chung FT, Lee CS, et al. Distancesaturation product of the 6-minute walk test predicts mortality of patients with non-cystic fibrosis bronchiectasis. J Thorac Dis. 2017; 9(9):3168-76.

81. Edwards EA, Metcalfe R, Milne DG, Thompson J, et al. Retrospective review of children presenting with non cystic fibrosis bronchiectasis: HRCT features and clinical relationships. Pediat Pulmonol. 2003; 36(2):87-93.

82. Svenningsen S, Guo F, McCormack DG, Parraga G. Noncystic Fibrosis Bronchiectasis: Regional Abnormalities and Response to Airway Clearance Therapy Using Pulmonary Functional Magnetic Resonance Imaging. Acad Radiol. 2017; 24(1):4-12.

83. Irving SJ, Davies JC, Alton EW, Bush U. Lung clearance index in primary ciliary dyskinesia and bronchiectasis. $A m$ J Respir Crit Care Med. 2014; 189(9):1147-8.

84. CHQ-GDL-01072. Empirical Antimicrobial Therapy for Children with Non-Cystic Fibrosis Bronchiectasis. [Acceso: 5 de agosto de 2020]. Disponible en: https://www. childrens.health.qld.gov.au/wp-content/uploads/PDF / ams / gdl-01072.pdf.

85. El Boustany P, Gachelin E, Colomban C, Cernoia JA, et al. Review of non-cystic fibrosis bronchiectasis in children with a focus on the role of long-term treatment with macrolides. Pediatr Pulmonol. 2019; 54(4):487-96.

86. NHS Royal Brompton Hospital. Clinical guidelines: Care of children with cystic fibrosis, 2017. $7^{\circ}$ ed. [Acceso: 5 de agosto de 2020]. Disponible en: https: / / www.rbht.nhs.uk/ sites / nhs / files / Cystic\%20fibrosis\%20guidelines / CF\%20 guideline $\% 202017 \% 20$ FINAL $\% 20-\% 2013 \% 201 \% 2017$.pdf. 


\section{ANEXO}

\section{Recomendaciones de tratamiento antibiótico de erradicación y crónico}

Su implementación debe estar consensuada con el equipo tratante o el especialista.

\section{Tratamiento de Pseudomonas}

- Primer aislamiento

Exacerbación con compromiso clínico. Tratamiento endovenoso:

Piperacilina/tazobactam: $100 \mathrm{mg} / \mathrm{kg} /$ dosis cada 6 h. Dosis máxima de $4 \mathrm{~g} /$ dosis de piperacilina. O

Ceftazidima + amikacina intravenosas por 2 semanas y luego continuar con tobramicina inhalada por 1 mes.

Exacerbación sin compromiso clínico con buen estado general. Tratamiento por vía oral:

Ciprofloxacina de 30 a $40 \mathrm{mg} / \mathrm{kg} /$ día por vía oral, por 14 días. O ciprofloxacina de 30 a $40 \mathrm{mg} / \mathrm{kg} /$ día por vía oral, por 3 semanas + colistimetato sódico inhalado cada 12 h (< de 1 año de edad: 1 millón de UI; > de 1 año de edad: 2 millones de UI por 3 meses. ${ }^{84,85} \mathrm{O}$ alternativa tobramicina a razón de $300 \mathrm{mg}$ cada 12 horas inhalada por un mes.

Luego de 3 cultivos negativos en 6 meses de haberse finalizado el tratamiento inhalado, se considera la erradicación confirmada. ${ }^{84,85}$

\section{- Si la erradicación no se logra:}

Exacerbación con compromiso clínico. Tratamiento endovenoso: se debe repetir el esquema inicial.

Piperacilina/tazobactam: $100 \mathrm{mg} / \mathrm{kg} /$ dosis cada $6 \mathrm{~h}$ con dosis máxima de $4 \mathrm{~g} /$ dosis de piperacilina. ${ }^{78,86}$ O ceftazidima + amikacina intravenosas por 2 semanas y luego continuar con tobramicina inhalada por 1 mes.

Exacerbación sin compromiso clínico con buen estado general. Tratamiento por vía oral:

Se debe repetir el esquema de primer aislamiento $y$, si persiste con cultivo positivo luego de esta $2^{\mathrm{da}}$ erradicación, continuar con tobramicina inhalada por un año (en meses alternos) y, al año del tratamiento, reevaluar.

- Infección crónica (más de la mitad de los cultivos positivos en un año):

Se debe continuar con tobramicina o colistimetato inhalado en meses alternos o continuos según el criterio clínico del médico en seguimiento. ${ }^{78,86}$

En pacientes con daño neurológico, las Pseudomonas pueden ser colonizantes de la vía aérea superior y, según el estado clínico, puede iniciarse el tratamiento empírico con amoxicilina/ clavulánico por vía oral o ceftriaxona. ${ }^{84}$

Las guías británicas 2010 recomiendan que, en los niños que cultivan P. aeruginosa sensible a la ciprofloxacina, se puede administrar como monoterapia por vía oral. ${ }^{35}$

En aquellos niños cuyos cultivos de esputo contienen patógenos con múltiples patrones de resistencia, se debe considerar la terapia con antibióticos combinados.

En la identificación de infección por Staphylococcus aureus resistente a meticilina, debe realizarse un programa de erradicación con la consulta previa con el especialista, que puede incluir un curso de antibióticos intravenosos. Si los antibióticos orales no tienen éxito, trimetoprima/sulfametoxasol (TMS). ${ }^{84}$

\section{Tratamiento crónico con azitromicina}

El uso de antibióticos de mantenimiento en bronquiectasias no FQ es restringido y requiere de la consulta previa con el especialista. Para ello, el niño debe estar monitoreado estrictamente con la consideración de suspender estos antibióticos si la respuesta no es la esperada o después de un período de 6 a 24 meses.

La azitromicina con propiedades antiinflamatorias e inmunomoduladoras se ha utilizado, a través de ensayos en niños y adultos, como terapia de mantenimiento durante 6-24 meses y su uso ha demostrado una reducción de exacerbaciones respiratorias en niños cuidadosamente seleccionados con bronquiectasias no FQ..$^{84,85}$ 


\section{Consideraciones antes de iniciar la terapia crónica:}

Presencia de bronquiectasias confirmada por TACAR de tórax

- El niño ha tenido $\geq 3$ exacerbaciones y / o $\geq 2$ hospitalizaciones en los 12 meses anteriores.

- El niño ha sido evaluado por el especialista en Neumonología Pediátrica.

- Ausencia documentada previamente de micobacterias no tuberculosas.

- Se debe realizar una prueba de función hepática y un electrocardiograma (determinación del QTc) y si hay otros factores de riesgo.

- En el seguimiento (mínimo a los 6 meses después del inicio), se debe reevaluar el beneficio de la azitromicina sobre la frecuencia de las exacerbaciones y otros aspectos clínicos.

- Se debe considerar repetir la prueba de función hepática cuando sea necesario.

- Ante la duda, se debe repetir el esputo (si se puede obtener) ante la falta de respuesta.

Programa de dosificación de profilaxis con azitromicina:

- Paciente de menos de $25 \mathrm{~kg}$ de peso: $10 \mathrm{mg} / \mathrm{kg} /$ dosis trisemanal (tres veces por semana).

- Paciente de 25 a $40 \mathrm{~kg}$ de peso: $250 \mathrm{mg} /$ dosis, tres veces por semana.

- Paciente $>40 \mathrm{~kg}$ de peso: $500 \mathrm{mg} /$ dosis, tres veces por semana.

\section{Se debe evaluar el beneficio:}

- Los pacientes que requieran azitromicina durante más de 6 meses necesitarán controles mensuales para evaluar el beneficio y el monitoreo de seguridad.

- Revisión formal por el equipo tratante.

- A los 12 meses, se debe controlar la reducción de la frecuencia y / o la gravedad de las exacerbaciones (tos húmeda o esputo; se debe controlar la función pulmonar o la mejoría en el bienestar general, por ejemplo, aumento de peso) y la adherencia del paciente o la familia: capacidad para un control periódico mientras reciben terapia a largo plazo. Vigilancia de los patrones de resistencia a macrólidos en los resultados de microbiología (si se puede obtener esputo).

Suspensión de azitromicina después de 6 a 24 meses (o antes) en los siguientes casos:

- El paciente no tolera el medicamento.

- No se demostró ningún beneficio clínico después de un ensayo de 6 meses con el antibiótico.

- Mejoría clínica espontánea anticipada.

- Se puede suspender la azitromicina para un período de prueba de 3 a 6 meses después de 24 meses de uso continuo, ya que hay datos limitados de seguridad y eficacia después de los 24 meses.

- Si, después de un ensayo de interrupción (2 meses o más sin azitromicina), el niño cumple los criterios de deterioro ( $\geq 3$ exacerbaciones $y / o \geq 2$ hospitalizaciones), la azitromicina puede ser reiniciada con control formal por el equipo tratante o el especialista para evaluar el beneficio a los 6 meses y cada 6 meses por los siguientes 12 meses.

- Anualmente, se debe intentar una prueba de 2 meses o más de cese de azitromicina para evaluar su continuidad. ${ }^{85}$ 